\title{
BMJ Open Lived experience of women with gestational diabetes mellitus living in China: a qualitative interview study
}

\author{
Li Ge, ${ }^{1}$ Kerstin Wikby, ${ }^{2}$ Mikael Rask ${ }^{1,2}$
}

To cite: Ge L, Wikby K, Rask M. Lived experience of women with gestational diabetes mellitus living in China: a qualitative interview study. BMJ Open 2017;7:e017648. doi:10.1136/ bmjopen-2017-017648

- Prepublication history for this paper is available online. To view please visit the journal online (http://dx.doi.org/10. 1136/bmjopen-2017-017648).

Received 6 May 2017

Revised 2 October 2017

Accepted 25 October 2017
CrossMark

${ }^{1}$ Nursing College, Fujian University of Traditional Chinese Medicine, Fujian, China ${ }^{2}$ Department of Health and Caring Sciences, Linnaeus University, Vaxjo, Sweden

Correspondence to Dr Li Ge;

2000005@fjtcm.edu.cn

\section{ABSTRACT}

Objective To explore the lived experience of women with gestational diabetes mellitus (GDM) living in China in order to add knowledge about how the Chinese women suffer from GDM.

Design A qualitative interpretive interview study. Data were collected with a snowball sampling technique. Phenomenological hermeneutics was used as the analysis method based on Ricoeur's phenomenological hermeneutical interpretation theory.

Setting The study was performed at the participants' work places, or at the obstetric clinics or wards at two provincial hospitals and one municipal hospital in the southeast of China.

Participants Inclusion criteria were age $\geq 18$ years, diagnosis of GDM without other pregnancy complications, in 34th gestational weeks-postpartum 4th weeks and speaking Mandarin Chinese without speech impediment. 62 women, who met the inclusion criteria, took part in the study.

Results The lived experience of the women with GDM living in China was formulated into a main theme: 'longing for caring care'. The main theme was derived from four themes: being stricken by GDM, wishing to receive caring GDM care, being left alone to struggle with GDM and trying to adjust and adapt to life with GDM.

Conclusion The eagerness for caring care in China was highlighted. The lack of caring care could be one of the possible reasons why the professional-patient relations were deteriorating in China. It could be useful for health providers and health policymakers to receive education and training about caring care. Using the health metaphor of balance and 'patient participation' and 'patient-centred' approaches may benefit women with GDM and thus improve the quality of care in China.

\section{INTRODUCTION}

Diabetes is a major health problem in China where the highest number of deaths in the world due to the illness has been recorded. ${ }^{1}$ One of the types of diabetes, gestational diabetes mellitus (GDM), is associated with type 2 diabetes mellitus (T2DM); women who have been previously diagnosed with GDM will run a greater risk of developing T2DM later in life and GDM in subsequent pregnancies. ${ }^{2}$ GDM plays a crucial role in the increasing

\section{Strengths and limitations of this study}

To our knowledge, this is the first study to explore the lived experience of women with gestational diabetes mellitus (GDM) living in China.

- A large number of participants $(n=62)$ presented the trustworthiness of the qualitative study.

- By using phenomenological hermeneutics, a greater understanding of the essential meaning of living with GDM in China could be attained.

- We could not free ourselves from our preunderstanding which could produce bias.

- Nuances could be lost in the translation process of the interview texts, which could influence the results of the study.

prevalence of diabetes and obesity. ${ }^{3}$ Uncontrolled GDM is also associated with serious complications for women with the illness and their fetus, for instance, obstructed labour and congenital abnormalities. ${ }^{3}$ According to a study in 2015 in Tianjin of China, the prevalence of GDM in China is $8.1 \%$ by using the WHO criteria. ${ }^{4}$ GDM is becoming a priority issue in public health of China. A recent study conducted in China reported that women living with GDM perceived a lack of highquality GDM care. ${ }^{5}$ According to Lindseth and Norberg, ${ }^{6}$ in order to be able to understand and improve healthcare practice, we have to start with the lived experience and express it in order to become aware of its meaning. This awareness itself often leads to improvements in the healthcare field.

The experiences of women with GDM in some socio-cultural contexts have been reported. In a metasynthesis study including studies from different countries worldwide, women with the illness experienced several negative feelings, such as fear and a loss of normality and personal control, ${ }^{7}$ as well as in another study performed in Australia they reported uncertainty and scepticism. ${ }^{8}$ Another review study ${ }^{9}$ not only revealed women's negative feelings and thoughts, but also explored the women's struggle to 
manage GDM and their identity changes from a healthy person to being someone with GDM; their adaptation to the changes; their concern for the health of their babies as well as their own health and their perception of seriousness of GDM and fear of T2DM. Furthermore, the experiences of Caucasian and South Asian women with GDM living in Canada illustrated a disconnection between diabetes prevention recommendations and the women's cultural practices. ${ }^{10}$ However, to our knowledge, little was known about the lived experience of women with GDM living in China.

Studies conducted in China showed that the beliefs and health-related behaviour among women with GDM living in China were influenced by Chinese social culture. ${ }^{11}{ }^{12}$ A review study revealed that the influencing factors of the experience of women living with GDM included cultural roles and beliefs, social stigmas, social and professional support, and social roles and barriers to self-care. ${ }^{9}$ In China, the social context is that the scale, frequency and viciousness of violence against health professionals have shocked the world. ${ }^{13}$ The increasing medical disputes including widely reported violent attacks, murders and protests in hospitals showed the deteriorating relationship between health professionals and patients. ${ }^{14}$ However, GDM seriously depends on good professional-patient relations in order to obtain satisfied effects of health education due to the strict routine and lifestyle management that women with GDM have to perform. ${ }^{15}$ Therefore, exploring the lived experience of women with GDM living in China would add knowledge of what it is like to live with GDM and how suffering it is for Chinese women. The study thus aimed to explore the lived experience of women with GDM living in China.

\section{METHODS \\ Design}

A qualitative interview study was conducted among women with GDM living in China by using phenomenological hermeneutics ${ }^{6}$ inspired by Paul Ricoeur. ${ }^{16}$

\section{Participants and setting}

The inclusion criteria of participants were age $\geq 18$ years, diagnosis of GDM without other pregnancy complications, ${ }^{17}$ in the 34 th gestational week-the postpartum 4 th week and speaking Mandarin Chinese without speech impediment. Sixty-two women who met the inclusion criteria took part in the study (table 1). The median age was 31 years (range 23-37). Four women refused to participate in the study, whose reasons were 'I don't have time' or 'I have to go back home now'. The study was performed at the participants' work places, or at the obstetric clinics or wards at two provincial hospitals and one municipal hospital in the southeast of China. A single room was chosen for each interview, which was most convenient for the participants.
Table 1 Characteristics of the interviewed Chinese women with gestational diabetes mellitus (GDM) $(n=62)$

\begin{tabular}{|c|c|c|}
\hline Variable & Median (range) & No \\
\hline Age (years) & $31(23-37)$ & 62 \\
\hline $\begin{array}{l}\text { 34th gestational week-before } \\
\text { birth }\end{array}$ & & 39 \\
\hline $\begin{array}{l}\text { Postpartum 1st week- } \\
\text { postpartum 4th week }\end{array}$ & & 23 \\
\hline Relapse in GDM & & 5 \\
\hline $\begin{array}{l}\text { GDM symptoms such as thirst } \\
\text { and ketoacidosis }\end{array}$ & & 9 \\
\hline \multicolumn{3}{|l|}{ Present treatment for GDM } \\
\hline No treatment & & 3 \\
\hline Diet & & 22 \\
\hline Diet+exercise & & 29 \\
\hline Diet+insulin & & 8 \\
\hline $\begin{array}{l}\text { Current nutritional supplements } \\
\text { such as multivitamin and minerals }\end{array}$ & & 55 \\
\hline Nulliparous & & 44 \\
\hline Parous & & 18 \\
\hline \multicolumn{3}{|l|}{ Educational level* (duration) } \\
\hline $\begin{array}{l}\text { Senior secondary education } \\
\text { (12-13years) }\end{array}$ & & 30 \\
\hline Higher education ( $\geq 15$ years) & & 32 \\
\hline \multicolumn{3}{|l|}{ Present working condition } \\
\hline Employed & & 30 \\
\hline Unemployed & & 25 \\
\hline Sick leave & & 7 \\
\hline \multicolumn{3}{|l|}{ Family circumstances } \\
\hline Married & & 61 \\
\hline \multicolumn{3}{|l|}{ Interview setting } \\
\hline Obstetric clinic & & 29 \\
\hline Obstetric ward & & 23 \\
\hline Participants' work place & & 10 \\
\hline
\end{tabular}

*The classification standard of educational level is according to China Statistical Yearbook 2014. ${ }^{34}$

\section{Interviews and analysis}

Participants were recruited by using a snowball sampling technique. ${ }^{18}$ Women with GDM were referred to the interviewee of the study by participants or by four midwives who worked at hospital, and were then orally invited to participate in the study. They were first informed of the aim and the procedures of the study, and were assured of the right to withdraw at any time without negative consequences. They were informed that all transcripts were anonymous, and the analysis of data and presentation of results were carried out in such a way that no individual could be identified. They took part in the study voluntarily, and their written informed consent was obtained.

Open-ended questions about the lived experience of women with GDM, which were developed by the 
Box Interview questions about the lived experience of women with gestational diabetes mellitus (GDM)

What are your experiences after you got to know that you had GDM?

What do you think about GDM?

- Which physical changes have you experienced after you got GDM?

- Which emotional changes have you experienced after you got GDM?

- How did you manage your GDM?

- How does GDM affect your life? (family and work)

What did you feel at the beginning when you got GDM?

What did you feel during the time living with GDM?

authors, were used for data collection (box). Individual narrative interviews were conducted face to face during August and December of 2014 by the first author, a native female Chinese with bilingual skills. Each interview lasted between 30 and $50 \mathrm{~min}$, and was recorded with a digital audio recorder and then transcribed verbatim in Chinese and translated from Chinese to English by the first author. Three pilot interviews were conducted and then discussed among the authors, which were included in this study based on their quality.

Phenomenological hermeneutics ${ }^{6}$ based on Ricoeur's phenomenological hermeneutical interpretation theory ${ }^{16}$ was used as the analysis method in this study. The analysis process consisted of three phases: naive reading, structural analysis and comprehensive understanding. In the naive reading, the transcribed interview texts were first merged into one text and then read several times as open-minded as possible in order to obtain its meaning as a whole. The maintenance of a phenomenological attitude was important during the naïve reading in order to formulate a naïve understanding of the text in phenomenological language.

In structural analysis, the whole text was read and divided into meaning units. The meaning units were read through and reflected on based on the background of the naïve understanding, and were then condensed and expressed in everyday words as concisely as possible. All the condensed meaning units were read through and reflected on regarding similarities and differences, and then were sorted, further condensed and abstracted to form subthemes. The subthemes were reflected on and formulated in such a way as to present what the text talked about, thus leading to the formulation of themes. Reflection about the themes was based on the naïve understanding, and these explored in terms of whether they validated or invalidated the naive understanding. If the structural analysis invalidated the naïve understanding, the whole text would be read again and a new naïve understanding would be formulated and checked by a new structural analysis. The process was repeated until the naive understanding was indeed validated through the structural analysis.

In the comprehensive understanding, the third analysis phase, the whole text was reread as open-minded as possible with the naïve understanding and the validated themes in mind. Imagination and preunderstanding were used during the process. Relevant literature that seemed appropriate for helping to revise, widen and deepen the understanding was discussed between authors based on the meaning of the lived experience. The literature that could mutually illustrate the interview text was chosen for interpreting the text. The text was kept as close as possible as a whole again and recontextualised in the light of the literature, and a comprehensive understanding of the text, that is, the main theme, was attained by focusing on the possibilities of living in the world that the interview text opened up. According to Ricoeur, ${ }^{16}$ a text could probably be interpreted in different ways, but the interpretation should be understood dialectically related to each other, overlap and interact with each other. Dialectical interpretation of the text and the meaning of the lived experience were achieved by discussion between the three authors.

\section{FINDINGS}

The lived experience of the women with GDM living in China was formulated into a main theme: 'longing for caring care'. The main theme was derived from four themes: being stricken by GDM, wishing to receive caring GDM care, being left alone to struggle with GDM and trying to adjust and adapt to life with GDM.

\section{Naïve analysis}

The women in the study described their initial emotional reactions when they were informed of the diagnosis of GDM. They experienced shock, doubt, surprise, feeling strange, denial, fear and worry. They reflected on the reasons of getting it and sought help from the health professionals and popular sectors, that is, relatives, friends, internet and books. It appears that they did not initially receive the satisfactory answers about GDM from the health professionals, so they sought help from the popular sector. They perceived that the information obtained about GDM was inconsistent. After considering all the information, women were always afraid of and worried about having the illness; or women believed it was not a severe illness; or women thought that it was nothing to worry about. The women's experiences of GDM contained distressed feelings caused by the illness, helplessness, confusion and neglectful attitude from health professionals and people around.

\section{Structural analysis}

Four themes emerged during the structural analysis including being stricken by GDM, wishing to receive caring GDM care, being left alone to struggle with GDM and trying to adjust and adapt to life with GDM. These themes were described with subthemes, condensation units and meaning units.

Being stricken by GDM

After women in the study were informed of the diagnosis of GDM, they were stricken by emotional chaos. They 
Table 2 Meaning unit, condensations, subthemes included in the first theme (being stricken by GDM)

\begin{tabular}{|c|c|c|}
\hline Meaning unit & Condensation & Subtheme \\
\hline $\begin{array}{l}\text { 'I felt that it was a shock when I knew I got GDM because GDM is a disease. I } \\
\text { never never thought I would get the disease ... I couldn't accept it in my heart at } \\
\text { the beginning.' (Participant 55) }\end{array}$ & Shock & \multirow{6}{*}{$\begin{array}{l}\text { Experiencing } \\
\text { different } \\
\text { emotional } \\
\text { reactions }\end{array}$} \\
\hline $\begin{array}{l}\text { 'At that moment when I was suddenly informed diabetes ... May be ... I thought } \\
\text { that this was a kind of deviation from the blood test ... an error.' (Participant 8) }\end{array}$ & $\begin{array}{l}\text { Doubt the diagnosis of } \\
\text { GDM }\end{array}$ & \\
\hline $\begin{array}{l}\text { 'I felt very strange at that moment because I didn't have the concept (of GDM) and } \\
\text { didn't know what GDM was. My husband also felt very strange. He said, "Hey, how } \\
\text { is pregnancy going with diabetes?” He felt very strange.' (Participant 9) }\end{array}$ & $\begin{array}{l}\text { Feel surprised and } \\
\text { strange }\end{array}$ & \\
\hline $\begin{array}{l}\text { 'I hoped in my heart that I didn’t get GDM. I would rather to believe other people's } \\
\text { words such as “You didn't get”, “Doesn’t matter” ... If I denied it, I would feel } \\
\text { relieved.' (Participant 49) }\end{array}$ & Deny & \\
\hline $\begin{array}{l}\text { 'I feared in my heart. Whether GDM would influence my baby if I couldn't control } \\
\text { well?! Whether GDM would influence me?! I almost cried at that time. How could } \\
\text { I get GDM? My family doesn't have the problem. Why I suddenly got it?! ... I was } \\
\text { scared.' (Participant 30) }\end{array}$ & Fear & \\
\hline $\begin{array}{l}\text { 'People always say that it is good to eat fruits, so I ate a big volume of fruits every } \\
\text { day. I ate five-six kinds of fruits per day. ... Moreover, I very like to eat sweet } \\
\text { potatoes. Maybe they are the factors that made me get GDM.' (Participant 18) }\end{array}$ & $\begin{array}{l}\text { Reflect the reasons of } \\
\text { getting GDM }\end{array}$ & \\
\hline
\end{tabular}

GDM, gestational diabetes mellitus.

were shocked and surprised, and felt strange at the beginning. Some of them could not accept the fact, and thus doubted and denied the diagnosis of GDM. Nevertheless, they were afraid of and worried about the negative effects of GDM on their babies and themselves. When the women experienced these emotional reactions, they also reflected on the reasons for getting the illness. They believed the reasons were eating too much fruits and sweets, obesity and advanced maternal age (table 2).

\section{Wishing to receive caring GDM care}

After the women saw the abnormal result of the OGTT, they began to seek help from different resources. A woman said, 'I consulted doctor and some friends who work in hospital ... I searched on the internet ... I was a little nervous, so I called my mother'. However, they perceived that the information received about the illness was inconsistent. They thought that the support and encouragement from health professionals and their husbands were important and could promote their health behaviour. They, however, perceived that the GDM care from health professionals was insufficient and uncaring. They complained about the health education from the professionals being unclear and lacking detail because of the large number of patients waiting. Some thought that the doctors and midwives were not professional about GDM and did not take the illness seriously. They wished to receive caring GDM care (table 3).

The obstetric doctor just said 'Observation'. I asked 'How do I observe?' She just said 'Come and check
OGTT again after a period'... The doctor still said 'Observation' after the second OGTT ... She at most said, 'Pay more attention to your life style, your diet, and your exercise.' I cannot feel they care about me. (Participant 5)

\section{Being left alone to struggle with GDM}

The beliefs and experiences of the women in the study could be divided into three styles: they believed the illness should be treated seriously, but felt distress; or they believed it was not a severe illness, but at the same time experienced helplessness; or they believed it was nothing to worry about and ignored the seriousness of having GDM. These personal beliefs and experiences showed that women in the study were left alone to struggle with GDM (table 4).

The women who believed GDM should be treated seriously thought that their health was their own and they should take responsibility for attaining a normal value for their blood glucose level. They were worried about or afraid of the negative effects of GDM, and strove to seek information from health professionals and control GDM. A participant explained her fear of T2DM in the future, which is one of the risks for women with GDM, as well as her notion about the desperate feeling of getting the lifetime disease. 'I'm particularly afraid of getting diabetes in the future ... You may imagine that the disease is getting worse and worse, and in one day you could be like the very sick person that you'd seen.' Some women even systematically 
Table 3 Meaning unit, condensations, subthemes included in the second theme (wishing to receive caring GDM care)

\begin{tabular}{|c|c|c|}
\hline Meaning unit & Condensation & Sub-theme \\
\hline 'I consulted doctor ...' (Participant 25) & $\begin{array}{l}\text { Seek help from health } \\
\text { professionals }\end{array}$ & Seeking help \\
\hline $\begin{array}{l}\text { 'When I don't want to insist on (GDM regime), I will visit my doctor. I often } \\
\text { go to do antenatal care. My doctor will encourage me, "Why did you not } \\
\text { test? How can you eat the milk tea? (The milk tea contains much sugar)" I } \\
\text { often talk with her. I am encouraged by her.' (Participant } 45 \text { ) }\end{array}$ & $\begin{array}{l}\text { Perceive support from health } \\
\text { professionals }\end{array}$ & \multirow{2}{*}{$\begin{array}{l}\text { Perceiving the } \\
\text { importance of } \\
\text { the support } \\
\text { from health } \\
\text { professionals and } \\
\text { husbands }\end{array}$} \\
\hline $\begin{array}{l}\text { 'After my husband knew my illness, he pays more attention to diet. } \\
\text { Sometimes I very want to have a taste on something such as ice cream } \\
\text { or cake, but he doesn't let me eat ... He pays more attention to my illness } \\
\text { than me. He urges me to do exercise ... At least, it shows that he cares } \\
\text { about me.' (Participant 16) }\end{array}$ & $\begin{array}{l}\text { Perceive support from } \\
\text { husbands }\end{array}$ & \\
\hline $\begin{array}{l}\text { 'It seems that the reference values of GDM are different at different } \\
\text { hospitals. The volume of the glucose powder used for OGTT test is } \\
\text { also different at different hospitals ... But the normal range of the } \\
\text { blood glucose was the same at the two hospitals. I thought that maybe } \\
\text { something was wrong, so I searched it in internet. There were many } \\
\text { different kinds of answers about it in internet. I could not understand.' } \\
\text { (Participant 60) }\end{array}$ & $\begin{array}{l}\text { Perceive inconsistent } \\
\text { information about GDM }\end{array}$ & $\begin{array}{l}\text { Perceiving } \\
\text { lack of caring } \\
\text { GDM care from } \\
\text { professionals }\end{array}$ \\
\hline
\end{tabular}

GDM, gestational diabetes mellitus.

searched for GDM knowledge. They fully complied with the advice of health professionals and gave up their previous unhealthy lifestyle and their favourite food, which could increase their blood glucose. They attained the stable normal value of blood glucose, but they felt distressed because of being restricted from enjoying food, the special way other people looked at and the pain caused by the needle pricks when self-monitoring blood glucose. A woman talked about their inner struggle about diet control, 'I can't see other people eating, so I have to go away if I see it. But I will still think about the food after I go away, and then come back to have a look ...'

The women who believed GDM was not a severe illness were affected by the views of 'GDM does not matter' from the health professionals and people around them. In terms of behaviour, the women with the style of belief controlled GDM based on the information they received. Once the value of their blood glucose was normal, the women thought that they recovered from GDM and returned to their previous customary lifestyle. However, some women felt helpless because they wanted to keep the value of their blood glucose in the normal range but the blood glucose could not be controlled well.

I think gestational diabetes isn't a big illness, but I want to be healthy ... I controlled according to doctor's advice ... Doctor said the same thing every time. She said that you paid attention to your diet. ... I try not to eat if I am not hungry. I only eat cucumber and tomato instead of fruit, because they contain little sugar. No way. I have tried my best to control it, but the values still aren't in the normal range. (Participant 40)

The women who believed GDM was nothing to worry about almost ignored GDM and did not know about the future risk of GDM. They thought that their GDM was nothing to worry about because the value of their blood glucose was only a little high; they had seen that the babies born by mothers with GDM were healthy and their physical body did not have abnormal symptoms. Some women even thought that GDM was not a disease at all. The women thought that they were influenced by the ignoring attitude of health professionals and people around them. A participant described the talking situation with her doctor about GDM, 'When the doctor showed me the test report, she didn't tell me that I got gestational diabetes. She only said that the value was a little high. So I didn't pay attention to it.' The women said that they asked different people after they were diagnosed with GDM. All the people around them said that there was nothing to worry about if the value of the blood glucose was just a little high; and the elderly always said that a big baby was good and very easy to 
Table 4 Meaning unit, condensations, subthemes included in the third theme (being left alone to struggle with GDM)

\section{Meaning unit \\ I' $m$ particularly afraid of getting diabetes in the future ... You may imagine that the disease is getting worse and worse, and in one day you could be like the very sick person that you'd seen.' (Participant 7) \\ 'I have been seriously controlling my blood glucose, actually it is because I fear... I fear that I would really get diabetes when I was old. I do fear my baby isn't healthy ... I adjusted my diet ... I did the regular monitoring of blood glucose ... I particularly wanted to control GDM well.' (Participant 7) \\ 'I feel very distressed about diet control. I am easy to be hungry. Even though I am hungry, I cannot eat ... I can't see other people eating, so I have to go away if I see it. But I will still think about the food after I go away, and then come back to have a look ... I feel sad sometimes.' (Participant 7)}

'I asked the doctor if I needed to test my blood glucose again when I did my next antenatal care. She said that it didn't matter, and let us see in the next month. After one month, I forgot to ask for checking my blood glucose when I came, she also forgot it. ' (Participant 21)

'My mother and other family think that many people got GDM which is very common, and GDM doesn't matter ... They always expect that I eat more foods ... They fear that my nutrition isn't enough because they feel that I don't eat this and that, and I have requirements on diet as well. They feel that I am too tense because I always very pay attention to many things during my pregnancy.' (Participant 5)

'I think gestational diabetes isn't a big illness, but I want to be healthy ... I controlled according to doctor's advice ... Doctor said the same thing every time. She said that you paid attention to your diet. ... I try not to eat if I am not hungry. I only eat cucumber and tomato instead of fruit, because they contain little sugar. No way. I have tried my best to control it, but the values still aren't in the normal range.' (Participant 40)

\begin{tabular}{|c|c|c|}
\hline $\begin{array}{l}\text { 'When the doctor showed me the test report, she didn't tell me that I got } \\
\text { diabetes. She only said that the value was a little high. So I didn't pay } \\
\text { attention to it.' (Participant } 36 \text { ) } \\
\text { 'My family thinks that GDM is nothing. Every day, they give me the fruit and } \\
\text { said, "Eat! It doesn't matter."...' (Participant 13) }\end{array}$ & $\begin{array}{l}\text { Be affected by the } \\
\text { neglectful attitude of } \\
\text { health professionals and } \\
\text { people around }\end{array}$ & $\begin{array}{l}\text { Believing GDM is } \\
\text { nothing to worry } \\
\text { about, and ignoring the } \\
\text { seriousness of having } \\
\text { GDM }\end{array}$ \\
\hline $\begin{array}{l}\text { 'My sister-in-law got gestational diabetes when she was pregnant. She } \\
\text { doesn't have diabetes after she gave birth. Her baby is also healthy. } \\
\text { Actually, the influence of gestational diabetes isn't big.' (Participant 13) }\end{array}$ & $\begin{array}{l}\text { Be affected by seeing } \\
\text { healthy babies whose } \\
\text { mother had GDM }\end{array}$ & \\
\hline $\begin{array}{l}\text { 'My physical body doesn't have any change, so I don't take gestational } \\
\text { diabetes as a severe problem ... I think that gestational diabetes isn't a } \\
\text { disease at all. ... I didn't visit doctor.' (Participant 8) }\end{array}$ & $\begin{array}{l}\text { Be affected by feeling } \\
\text { no physical body } \\
\text { symptoms }\end{array}$ & \\
\hline $\begin{array}{l}\text { 'I don’t know what influence gestational diabetes will bring to me.' } \\
\text { (Participant 8) }\end{array}$ & $\begin{array}{l}\text { Don't know the future } \\
\text { influence of GDM }\end{array}$ & \\
\hline
\end{tabular}

GDM, gestational diabetes mellitus.

bring up. In terms of behaviour, they almost did nothing related to GDM.

\section{Trying to adjust and adapt to life with GDM}

The women in the study had been trying to adjust and adapt to their lives with GDM during their pregnancy. With their fetus growing, they adapted to being a mother with GDM and gradually began to enjoy the feeling of being a mother. They believed that their emotions would influence their baby's personality and the health of their babies and themselves. They and their baby would be in a good situation if they were in a good mood. They thus tried to be happy.

\section{Condensation Subtheme}

Have been worrying Believing GDM should about or afraid of the be treated seriously, but negative effects of GDM feeling distressed

Strive to control GDM

Feel distressed

Be affected by the view of 'GDM not mattering' from professionals and people around them

ing GDM is not a severe illness, but at the same time experiencing helplessness

Control GDM based

on the received

information, but feel

helplessness 
Table 5 Meaning unit, condensations, subthemes included in the fourth theme (trying to adjust and adapt to life with GDM)

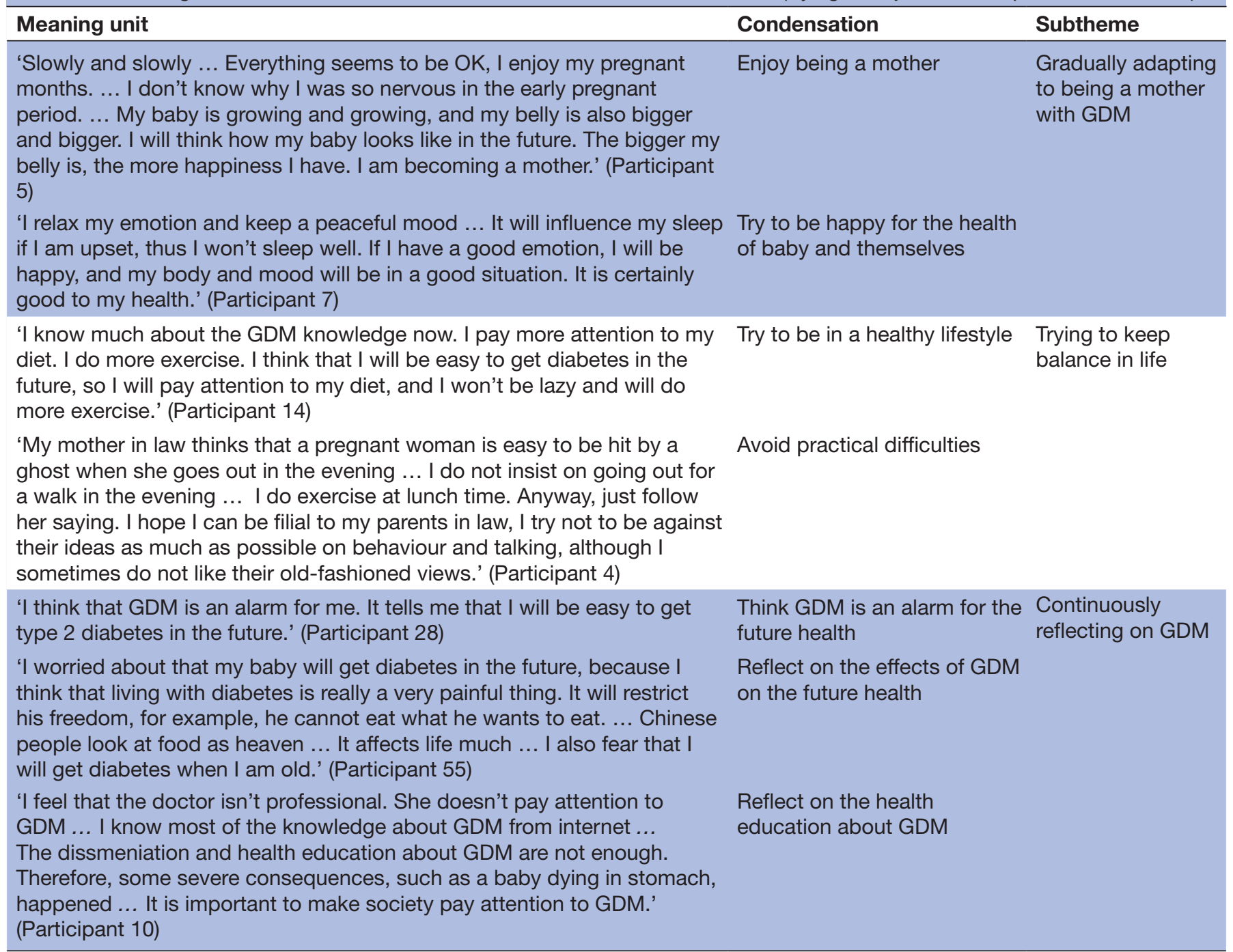

GDM, gestational diabetes mellitus.

the illness should be prevented at the beginning of a pregnancy and that the knowledge about GDM should be disseminated to everyone in society (table 5).

\section{Comprehensive understanding}

The women with GDM in the study seemed to be suffering due to their illness, treatment and lack of caring care. They complained about the neglectful attitude to GDM among health professionals, as well as a lack of health education about GDM and an understanding of GDM from the whole society. It seemed that they were eager to receive professional care and not be left alone to struggle with GDM. A study showed that good care from the patients' perspectives was patient-focused, individualised and involved care related to their needs; it was provided in a humanitarian way by the health providers who presented their involvement, commitment and concern to patients. ${ }^{19}$ Martinsen points out that caring includes having consideration for, being concerned about and taking care of the other. ${ }^{20}$ According to Eriksson, ${ }^{21}$ caring, as an ethos of love and compassion, implies alleviation of suffering in love, charity, faith and hope, and serves life and health. Based on the literature, our comprehensive understanding of the women's narratives was formulated as 'longing for caring care'.

\section{DISCUSSION}

The Chinese women experienced being stricken by emotional chaos after they were diagnosed with GDM. When seeking care, they wished to receive caring GDM care. When they struggled with GDM, their beliefs and experiences showed that they were left alone. However, they tried to adjust and adapt to life with GDM. Their lived experience showed that they longed for caring care.

The women in the present study experienced emotional chaos such as doubt and fear. Similar emotional reactions were showed in a metasynthesis study about perceptions among women with GDM. ${ }^{7} \mathrm{~A}$ study conducted in Canada showed that the strict regime 
such as diet control increased the women's anxiety and stress during pregnancy. ${ }^{22}$ These studies illustrated that women's experiences of living with GDM could be overwhelming. Moreover, women who believed that GDM should be treated seriously strove to control the illness and attained a stable normal blood glucose level, which was similar to other study findings. ${ }^{23}$ However, they felt distressed with the strict GDM regime. Some women felt unsupported by health professionals and their own close contacts/family on the GDM regime. They were left alone to face to the distress. A study has showed that the psychological aspect was pivotal in helping and encouraging women with GDM to promote self-management of the illness and better control of it. ${ }^{24}$ It is suggested that health providers and the women's family members needed to have an understanding and care of the women's psychological well-being and ongoing mental health.

Meanwhile, some women in the present study believed that GDM was not a severe illness or that GDM was nothing to worry about, but they felt helplessness or unawareness. One of the reasons for this was the women's perception of GDM: they did not perceive that they had any symptoms; they and their babies were 'normal' after being checked in hospital and they had seen other women with GDM and these women's neonates did not have any problems generated by GDM. A study showed that a lower level of risk awareness about GDM was related to limited knowledge about the body and GDM. ${ }^{23}$ Another study showed that lower levels of health literacy and risk awareness of GDM might relate to a risk for poorer self-management of GDM. ${ }^{25}$ The present study showed that these women's poorer self-management of GDM related to a lack of necessary knowledge about GDM. For example, one of their misunderstandings on diet control was that they returned to their previous diet once the value of their blood glucose was normal. Another aspect of the reasons for having the beliefs was due to the influence of the neglectful attitude to GDM of health professionals and people around. The women in the study complained that they lacked sufficient health education about GDM. They were left alone by health professionals and people around them. According to Helman, ${ }^{26}$ people suffering from physical discomfort or emotional stress seek help from professional, popular and folk sectors, and thus form their own beliefs and behaviour. They construct their reality of health and illness in aspects of biological and mental patterns, characteristics of their image of body, mind and soul, ethnicity and family structures of community and society, and experiences of care. The present study showed that women's beliefs were influenced by health professionals and people around them. Orem stated that nursing systems are action systems formed by health providers through the practice of their nursing agency for persons with health-derived or health-associated limitations in selfcare or dependent care. ${ }^{27}$ The nursing systems may be produced for individuals, for persons who constitute a dependent care unit and for families and other multiperson units. Therefore, in order to support the women and promote the women's health-related behaviour in the healthcare system, the neglectful attitude to GDM of some of the health providers ought to be changed; health education about GDM should involve women with GDM, their family members, communities and society.

Moreover, women in the present study tried to adjust and adapt to life with GDM. They adapted gradually to being a mother with GDM, tried to keep a balance in life and reflected continuously on GDM. A study in a group of Cambodian women showed that the core perception of health was 'seeking life balance'. ${ }^{28}$ Physical, emotional, spiritual, psychological and social considerations play different roles in the need for balance. According to Roy, ${ }^{29}$ health is a reflection of adaptation, that is, the interaction of the person and the environment aimed to be a state and a process of being and becoming integrated and a whole human being. In the present study, women presented the process of adjusting and adapting to life with GDM to attain the physiological, psychological and social integrity. Using the health metaphor concerning balance may thus be better for the health education of women with GDM than the more conventional methods of control and restriction. Making health providers understand patients' needs and thus help patients to reach a life balance, using 'patient participation' and 'patient-centred' approaches, may benefit the women with GDM.

Based on the lived experience, the women in the present study seemed to be suffering due to their illness, treatment and lack of caring care. The feeling of caring is generated by the resonance between patients and caregivers, and the acknowledgement of the individual with respect from a person-centred perspective ${ }^{30}$ A study showed that good care from the patients' perspectives was patient-focused, individualised and involved care related to their needs; nor, conversely, care was described as 'not so good', which was given in an impersonal manner, routine-based, unrelated to needs, and by staff who were distant and did not know or were not involved with the patients. ${ }^{19}$ According to Eriksson, ${ }^{21}$ patients' experiences of suffering related to care are not to be taken seriously, not to be welcome, being blamed and being subjected to exercise of power. The present study presented the suffering related to care and reflected on women's eagerness to caring care. The lack of caring care in the study could be a possible explanation why the professional-patient relations are declining in China. It is thus necessary, in professional context, to strengthen caring care for women with GDM in China. Caring, however, requires education and training ${ }^{20}$ and thus in order to update and perform the diabetes guidelines and routines with a humanistic care approach, it would be beneficial if health providers and 
health policymakers received education and training about caring care.

\section{STRENGTHS AND LIMITATIONS}

To our knowledge, this is the first study to explore the lived experience of women with GDM living in China. However, the essence of people's lived experiences is what is invariable in all the variations of the phenomenon and is not easily expressed by people. ${ }^{31}$ By using phenomenological hermeneutics ${ }^{6}$ a greater understanding of the essential meaning of living with GDM in China can be attained, which is possible to make stakeholders related to an illness understand each other better and thus improve healthcare practice. The ordinary world of women living with GDM could thus be transcended in the search of the true knowledge by the evidence of their lived experiences. ${ }^{31}$ Moreover, the large number of participants $(n=62)$ also presented the trustworthiness of the qualitative study.

However, we cannot be free ourselves from our preunderstanding, which could produce bias. ${ }^{32}$ Through critical reflection, discussion between authors and using relevant literature, we revised, broadened and deepened our awareness, and reduced the bias from our preunderstanding. Meanwhile, losing nuances in the translation process of the interview texts could be another limitation of the study. ${ }^{33}$ In order to reduce the translation problems, the first author, who had bilingual skills and had accepted the training of qualitative research methodology, transcribed the interviews verbatim in Chinese and translated the texts into English.

\section{CONCLUSIONS}

The eagerness for caring care in China was highlighted in the study. The lack of caring care could be one of the possible reasons why the professional-patient relations in China were deteriorating. The results of this study could be used as a contribution to strengthen caring care in China by carrying out and updating diabetes guidelines and routines with aspects of humanistic and psychological care, and training health providers in caring care. Using the health metaphor concerning balance and 'patient participation' and 'patient-centred' approaches may benefit the women with GDM and thus improve the quality of GDM care.

Acknowledgements The authors would like to express sincere appreciation to all the women who took part in the study. The authors thank the healthcare staff for assistance in recruiting participants. The authors are also grateful to Professor David Brunt for revising the manuscript.

Contributors All authors meet the criteria for authorship and have approved the final article. Data analysis, study design, manuscript preparation and final approval of the version to be submitted: LG, KW and MR. Data collection: LG.

Competing interests None declared.

Patient consent Obtained.
Ethics approval The Ethical Committee of Fujian University of Traditional Chinese Medicine, China (no. 2012-033), and all conducted procedures conformed to the principles of Declaration of Helsinki.

Provenance and peer review Not commissioned; externally peer reviewed.

Data sharing statement The unpublished data are available to all readers if they would like to read. The data without personal information can be provided by email.

Open Access This is an Open Access article distributed in accordance with the Creative Commons Attribution Non Commercial (CC BY-NC 4.0) license, which permits others to distribute, remix, adapt, build upon this work non-commercially, and license their derivative works on different terms, provided the original work is properly cited and the use is non-commercial. See: http://creativecommons.org/ licenses/by-nc/4.0/

(c) Article author(s) (or their employer(s) unless otherwise stated in the text of the article) 2017. All rights reserved. No commercial use is permitted unless otherwise expressly granted.

\section{REFERENCES}

1. IDF Diabetes Atlas Group. Update of mortality attributable to diabetes for the IDF Diabetes Atlas: Estimates for the year 2013. Diabetes Res Clin Pract 2015;109:4615

2. International Diabetes Federation. IDF diabetes Atlas. 7th edn. Belgium: Brussels, 2015.

3. Veeraswamy S, Vijayam B, Gupta VK, et al. Gestational diabetes: the public health relevance and approach. Diabetes Res Clin Pract 2012;97:350-8.

4. Leng J, Shao P, Zhang C, et al. Prevalence of gestational diabetes mellitus and its risk factors in Chinese pregnant women: a prospective population-based study in Tianjin, China. PLoS One 2015;10:e0121029-12.

5. Ge L, Wikby K, Rask M. Quality of care from the perspective of women with gestational diabetes in China. Int J Gynaecol Obstet 2016;134:151-5

6. Lindseth A, Norberg A. A phenomenological hermeneutical method for researching lived experience. Scand J Caring Sci 2004;18:145-53.

7. Parsons $\mathrm{J}$, Ismail K, Amiel S, et al. Perceptions among women with gestational diabetes. Qual Health Res 2014;24:575-85.

8. Morrison MK, Lowe JM, Collins CE. Australian women's experiences of living with gestational diabetes. Women Birth 2014;27:72-2.

9. Devsam BU, Bogossian FE, Peacock AS. An interpretive review of women's experiences of gestational diabetes mellitus: proposing a framework to enhance midwifery assessment. Women Birth 2013;26:e69-e76.

10. Kaptein S, Evans M, McTavish S, et al. The subjective impact of a diagnosis of gestational diabetes among ethnically diverse pregnant women: a qualitative study. Can J Diabetes 2015;39:117-22.

11. Ge L, Albin B, Hadziabdic E, et al. Beliefs about health and illness and health-related behavior among urban women with gestational diabetes mellitus in the south east of China. $J$ Transcult Nurs 2016;27:593-602.

12. Ge L, Wikby K, Rask M. 'Is gestational diabetes a severe illness?' exploring beliefs and self-care behaviour among women with gestational diabetes living in a rural area of the south east of China. Aust J Rural Health 2016;24:378-84.

13. Listed N. Violence against doctors: Why China? Why now? What next? Lancet 2014;383:1013.

14. He AJ, Qian J. Explaining medical disputes in Chinese public hospitals: the doctor-patient relationship and its implications for health policy reforms. Health Econ Policy Law 2016;11:359-78.

15. Ge L. Women's call for caring care: perspectives of Chinese women with gestational diabetes mellitus about beliefs, self-care behavior, quality of care and lived experience [dissertation. Sweden: Linnaeus University, 2016.

16. Ricoeur P, Thompson JB. Hermeneutics and the human sciences: essays on language, action and interpretation. New York: The Press Syndicate of the University of Cambridge, 1981.

17. Yang HX. Diagnostic criteria for gestational diabetes mellitus (WS 331-2011). Chin Med J 2012;125:1212-3.

18. Patton MQ. Qualitative research and evaluation methods.3th edn London: Sage Publications, 2002. 
19. Attree M. Patients' and relatives' experiences and perspectives of 'Good' and 'Not so Good' quality care. J Adv Nurs 2001;33:456-66.

20. Martinsen K, Kjerland LE. Care and vulnerability.Oslo: Akribe, 2006.

21. Eriksson K. The suffering human being. Chicago: Nordic Studies Press, 2006.

22. Hui AL, Sevenhuysen G, Harvey D, et al. Stress and anxiety in women with gestational diabetes during dietary management. Diabetes Educ 2014;40:668-77.

23. Hjelm K, Berntorp K, Apelqvist J. Beliefs about health and illness in Swedish and African-born women with gestational diabetes living in Sweden. J Clin Nurs 2012:21:1374-86.

24. Stankiewicz G, Mccauley K, Zhao L. Psychological issues for women diagnosed with gestational diabetes mellitus. Aust Nurs Midwifery $J$ 2014;22:39-41.

25. Carolan M, Steele C, Margetts H. Attitudes towards gestational diabetes among a multiethnic cohort in Australia. $J$ Clin Nurs 2010;19:2446-53.

26. Helman C. Culture, health and illness. 5th edn. London: Hodder Arnold, 2007.
27. Orem DE. Nuring: Concepts of practice. 6th edn. St.Louis: Mosby, 2001.

28. Catolico O. Seeking life balance: the perceptions of health of Cambodian women in resettlement. J Transcult Nurs 2013;24:236-45.

29. Garon M. Roy adaptation model: Sister Callista Roy. In:George JB, ed. Nursing theories: the base for professional nursing practice. Upper Saddle River: N.J.Pearson Education, 2011:e:291.

30. Wolf ZR, Bailey DN. Patersonand Zderad's humanistic nursing theory: concepts and applications. Int J Hum Caring 2013;17:60-9.

31. Jay M. Phenomenology and lived experience. Charlottesville: University of Virginia Press, 2011.

32. Heidegger M, Macquarrie J, Robinson E. Being and time. New York: HarperPerennial/Modern Thought, 2008.

33. Al-Amer R, Ramjan L, Glew P, et al. Translation of interviews from a source language to a target language: examining issues in crosscultural health care research. J Clin Nurs 2015;24:1151-62.

34. National Bureau of Statistics of China. China statistical yearbook, 2014. http://www.stats.gov.cn/tisj/ndsj/2014/zk/html/Z2102e.htm (accessed 1 Apr 2017). 